\title{
Awareness Mental Health During Pregnancy in Practice Midwife of Bogor, Jawa Barat
}

\author{
Nurul Husnul Lail ${ }^{1,2}$, Rizanda Machmud ${ }^{1}$, Yusrawati $^{1}$, Adnil Edwin ${ }^{1}$ \\ ${ }^{1}$ Program Doktoral, Medicine Faculty, Universitas Andalas, ${ }^{2}$ Health Science Faculty, Universitas Nasional
}

\begin{abstract}
Mental health problems in pregnancy still lack the attention of midwives, which is identified in the low mental health checks of pregnant women during ante natal care. A subsequent research was conducted by Idaiani in Jakarta and Bogor regions 2018 regarding the incidence of Perinatal Depression that reached $18.6 \%$ in Bogor region.
\end{abstract}

This research was a qualitative research and was conducted January 2019 in Independent Midwifery Practice in Bogor. The subjects of this research were The interview was conducted with 15 informants, they were one person from the ministry of health, coordinating midwives, chairmen of Indonesian midwives' branch associations in Bogor with total of 5 midwives who provided services in independent midwifery practice and as a key is 3 woman pregnant and three families of pregnant women, data were analyzed by using triangulation analysis.

Based on result of the research, The Construction Model Mental Health on Mothers during pregnancy in Independent Midwifery Practice is very important and needs attention. Pregnancy is still considered as a physical change that needs to be intervened because it is easier to be handled and detected. Maternal examination during pregnancy is carried out by Midwives in the implementation of mental health checks during pregnancy for pregnant women and this role has not been carried out optimally.

This research suggests conducting socialization with midwives as well as across related sectors to get political support in carrying out activities in health facilities and independent practice midwives.

Keywords: Pregnancy, Mental Health, Nurul's Model.

\section{Introduction}

Mental health problems in pregnancy still lack the attention of midwives, which is identified in the low mental health checks of pregnant women during ante natal care Mental illness during pregnancy is a public health problem that should be focused on seriously. $10-20 \%$ women in the world experienced mental health problem during the first stage of labor. The common

\footnotetext{
Corresponding Author:

Nurul Husnul Lail

Program Doktoral, Medicine Faculty, Universitas Andalas, Health Science Faculty, Universitas Nasional e-mail: nurulhusnul76@gmail.com
}

mental illness experienced by women include antenatal and postnatal depression, obsessive-compulsive, post-trauma stress, and post-partum psychosis. The prevalence of mental illness or mental health problem during pregnancy in low-income countries reached $15.6 \%$. One of five women experienced mental health issues during pregnancy such as depression, acute anxiety and fear towards labor, and mild to moderate emotional disorders. Depression and anxiety are common during pregnancy. The prevalence rates of $6 \%$ and $17 \%$ have been reported for major and minor depression, respectively. Meanwhile, the prevalence rate of anxiety symptom is reported for $23 \%$ due to change in appearance which affects the self-efficacy, and $15 \%$ for anxiety during antenatal period due to the feeling of unworthiness caused by pregnancy. 
According to Word Health Organization (WHO), around $10 \%$ of pregnant women and $15 \%$ of postpartum women experienced mental illness, especially depression. The prevalence rate is even higher in developing countries that reach $15.6 \%$ during the pregnancy and $19.8 \%$ towards the labor.

Some studies focused on decreasing the effect of pregnancy to mental health - psychology, stress and depression, knowledge, empowerment, and self-efficacy by improving the quality of pregnancy examination with antenatal care. Health workers are responsible to provide education on psychosocial condition of pregnancy to pregnant women ${ }^{8}$. Besides, additional care during pregnancy should also be provided by health workers (obstetric, midwife, and nurse). This attempt is needed to foster empathy among the health workers and encourage pregnant women to check their condition; which in the long term will decrease the adverse psychological condition during the pregnancy, after pregnancy, and child care

Mental health problem and other issues during pregnancy can be dangerous for the pregnant women and their children. The children might experience premature birth, low birth weight, and others. In addition, social stigma, low self-efficacy, and negative perception will encourage pregnant women to visit the health facilities.

The prevalence rate of depression during pregnancy in Indonesia has reached $22.4 \%$ that may increase the morbidity and mortality rates of mother and children during the pregnancy and postpartum periods. Mental health problems caused adverse effects to the pregnancy and the baby.

\section{Material and Method}

This research was a qualitative research with explorative primary data approach. The interview was conducted with 15 informants, they were one person from the ministry of health, coordinating midwives, chairmen of Indonesian midwives' branch associations in Bogor with total of 5 midwives who provided services in independent midwifery practice and as a key is 3 womant pragnant and three families of pregnant women, informant with under review theme and was an understanding of mental health in pregnant women and the members of Indonesian midwives' branch associations to reveal the cause-effect finding. The samples were taken by using consecutive sampling as nonprobability technique. The research time was around
January in 2019.

The data analysis was carried out by triangulation approach: source analysis and thematic analysis.

\section{Results}

\section{Perception on Mental Health during Pregnancy}

The definition of Information on Mental Health of Pregnant Women

Mental health during pregnancy regarding mental health of midwife informants is a state of mental disorders/illness in pregnant women such as depression, stress, anxiety "Mental health of pregnant women is a mental condition of pregnant women who are disturbed, mental illness usually because pregnant does not have a husband, pregnant because of rape victims so that his soul is disturbed" (Inf 1)

"Mental Health Pregnant women are the ones who know mental health. There are pregnant women who are stressed because they could be left by their husbands, or they could be due to unintended pregnancy. If there is only a general program, if there is no examination tool at the midwifery independent practice, they words are not understandable and they like to laugh, just take them to the general practitioner. For the examination of pregnant women, I used the standard, which was $10 \mathrm{~T}$, as far as I know, there is no psychiatric check for pregnant women. Obstacles do not exist if there is a new expression and we have to consult a general practitioner "(Inf 2)

"Mental health is a healthy condition not just a body but it must also be healthy inside but it is unclear whether it has become a standard in pregnancy examinations and there is no program as far as I know" (Informant 3).

"Mental health is the definition in the law of pregnant women undergoing physical, mental and social changes, to get healthy children the mother must be physically, mentally and socially healthy, then midwives need to oversee the health of these women, they are in professional standards, midwives only check the stomach, then help the childbirth. Modules do not exist yet, but there were many references, so when preparing the health of women to become mothers, it must be include the physical, mental and social health. Many factors influence among others, like, social, cultural, political, economic, policy factors. There are no obstacles, one of which is due to the limited understanding and ability of midwives in carrying out 
their role of being a reliable and competent midwife, due to the lack of formation in the education process, so that graduates become midwives don't know what to do. The lack of public awareness, about the importance of preparing to give birth to a future generation of quality, there is no pregnancy planning, Therefore midwifery care must be comprehensive and sustainable, respecting the uniqueness of women.

Table 1. In-depth Interviews about the Definition of Mental health on Pregnant Women

\begin{tabular}{|l|l|l|}
\hline Thematic & Answers & Conclusion \\
\hline $\begin{array}{l}\text { Definition of Mental } \\
\text { Health on pregnant } \\
\text { women }\end{array}$ & $\begin{array}{l}\text { - Disruptive mental illness during pregnancy (inf 1). } \\
\text { - To have a healthy child, the mother must be physically, mentally and } \\
\text { socially healthy, so midwives need to monitor women's health (inf 4) }\end{array}$ & $\begin{array}{l}\text { The mental health of pregnant } \\
\text { women is a state of being } \\
\text { prosperous and productive } \\
\text { during pregnancy. }\end{array}$ \\
\hline
\end{tabular}

Based on the document review, the definition of mental health is a condition of well-being in which a person realizes his own potential, she can deal with stress normally in her life, work productively and profitably, and is able to contribute to herelf or his community. ${ }^{14}$
The results of in-depth interviews and document review of the definition of Mental Health for Pregnant Women can be seen in the following table:

Table 2. Triangulation of Informants on the Definition of Maternal Mental Health

\begin{tabular}{|c|c|c|c|}
\hline Thematic & Interview & Document Review & Interpretation \\
\hline $\begin{array}{l}\text { Definition } \\
\text { of Mental } \\
\text { Health on } \\
\text { Pregnant } \\
\text { Women }\end{array}$ & $\begin{array}{l}\text { Mental Health for Pregnant Women is based on a document } \\
\text { review, the definition of Mental health is a condition of } \\
\text { well-being in which a person realizes her own potential, } \\
\text { can deal with stress normally in her life, work productively } \\
\text { and profitably, and is able to contribute to herself or her } \\
\text { community. }\end{array}$ & $\begin{array}{l}\text { Mental health problems } \\
\text { have not been recorded } \\
\text { in the documentation of } \\
\text { midwifery care for all } \\
\text { pregnant women }\end{array}$ & $\begin{array}{l}\text { Based on the results of } \\
\text { interviews and document } \\
\text { review, midwives have not } \\
\text { been able to explain the } \\
\text { definition of Mental Health } \\
\text { for Pregnant Women }\end{array}$ \\
\hline
\end{tabular}

\section{Factors Affecting Mental Health}

The factors that affect mental health of pregnant women according to several informants are as follows:

“......... Mental health will be caused by many things, especially if a pregnant woman knows about her pregnancy, preparation and support from her husband, from her family as well as her surroundings. Feeling supported by husband greatly improves the mental health of pregnant women, however, the formation of a sense of comfort and peace in pregnant women will be formed from the people and the environment closest to the pregnant mother. However, the condition of pregnant women, such as being irritable, disrespected and feeling unsure, can also affect the mental health of pregnant women, for this thing, it is necessary to support and strengthen health workers, such as midwive, whose place are often used by pregnant women to check their pregnancy... (Informant 1)

“........... The mental health of pregnant women, on average, is caused by their husband or spouse. Many pregamnat women are stressed because of the lack of support from their husbands, but now it cannot be denied that the economic situation is rather difficult so pregnant women are needed to be strenghtened so that they are not spoiled, they must be given education by midwives so that they are strong and can respect their life cycle, their nature and confidence with their abilities. (inf 12) . Mental health in pregnant women sometimes becomes stressful because they already have many children, the difficult in economic problems, husbands rarely stay home, disturbances or illnesses during pregnancy, lack of information from midwives about pregnancy, unplanned pregnancy, unintended pregnancy, ... . (inf 6) 
Table 3. In-depth Interview Factors affecting mental health

\begin{tabular}{|l|l|l|}
\hline Thematic & Answers & Conclusion \\
\hline \multirow{2}{*}{$\begin{array}{l}\text { Factors affecting } \\
\text { mental health of } \\
\text { pregnant women }\end{array}$} & $\begin{array}{c}\text { Knowledge about pregnancy, social support from both husband } \\
\text { and family, the role of health workers, especially midwives, the } \\
\text { ability of pregnant women ... (inf 1) }\end{array}$ & $\begin{array}{l}\text { Mental health factors for pregnant women } \\
\text { are social support, especially midwives } \\
\text { support such as Self Esteem and Self } \\
\text { Efficacy. }\end{array}$ \\
& $\begin{array}{l}\text { Self-readiness of pregnant women, comorbidity, husband's } \\
\text { support, the role of a midwife ... (inf. 16) }\end{array}$ & .
\end{tabular}

Based on a document review, the factors that influence mental health are social support, self-esteem, and selfefficacy in pregnant women related to mental health.

Table 4. Informants of Triangulation about factors that affect the mental health on pregnant women

\begin{tabular}{|l|l|l|l|}
\hline Thematic & Interview & Document Review & Interpretation \\
\hline $\begin{array}{l}\text { Factors affecting } \\
\text { Mental Health of } \\
\text { Pregnant Women }\end{array}$ & $\begin{array}{l}\text { Factors affecting mental } \\
\text { health of pregnant women } \\
\text { are support from husbands }\end{array}$ & $\begin{array}{l}\text { Factors affecting the Mental } \\
\text { Health of Pregnant Women } \\
\text { have not been documented }\end{array}$ & $\begin{array}{l}\text { Based on the results of interviews and } \\
\text { document review, factors affecting the mental } \\
\text { health of pregnant women, social support, } \\
\text { Self Esteem and Self-efficacy }\end{array}$ \\
\hline
\end{tabular}

\section{Programs and Barriers to Maternal Mental Health:}

Maternal Mental Health Program: Mental Health Program for pregnant women according to several informants; 1 Midwife, 1 midwifery coordinator, 1 Head of IBI, Head of Health Promotion of the Health Service and the Ministry of Health's Directorate of Mental Health, are programs for handling cases of mental disorders or mental disorders in pregnant women. The following is an excerpt from the informant's statement:

“..... The mental health program for pregnant women is a program that has been around since 2018 with MITO, this means that midwives already have a legal law so they must detect the extent of the mental health of pregnant women. This activity is currently being implemented in East Jakarta, and has not been socialized to the Regional Level Implementers. This program has not been evaluated even though this program has been launched since 2018 ......., (Informant (1 Directorate of Mental Health, Ministry of Health)

A mental health program for pregnant women in particular does not yet exist, but in general, a general mental health program for anyone has been conducted in every Public Health Centre, mental health is important for pregnant women so that pregnant women are relax in facing their pregnancy and It should have been included in the service when a pregnancy check was carried out. Midwives as the first person and staff that pregnant women always meet must be able to carry out this mental health check, but they doubt pregnant women can go to a doctor ... (Informant (2. Head of Health Promotion, Bogor District)

“.......... Mental health programs have been carried out by midwives such as Post Partum Blues. And if for pregnant women with mental disorders Schizophrenic or mental illness does not yet exist, it will only begin to be planned at the Ministry of Health and there has not been any implementation but competent midwives have to be able to identify for example the Post Partum Blues. The Ministry of Health will certainly work together with psychiatry (associations) to be able to discuss this mental health so that it does not become a danger to both mother and the fetus, also for all health workers associated with pregnant women service providers. And this will be comprehensive so that midwives and health workers must be able to communicate with pregnant women and their families including husbands Head of IBI) “

Mental Health Program has not provided the program yet, even during the pregnancy checkup was $10 \mathrm{~T}$ and had not started yet for the mental health check. There are only those for Baby Blues, Post Partum Depression but there were not much that have been detected which are only checked in the $\mathrm{Kf} 1 \mathrm{Kf} 2 \mathrm{Kf} 3$ standard, usually in physical conditions such as dizziness due to low HB, breast milk production, complaints of Trobophlebitis, indeed mental health is sometimes neglected so midwives do not pay attention to this. For 
mental health programs, it does not have to be specific but must be included in the examination of midwives for pregnant, childbirth and postpartum mothers ... Informants (4. BIKOR)

.......... The mental health program for pregnant women does not exist, in pregnancy examinations there is also no mental health, it is usual to check for pregnancy according to the standard $10 \mathrm{~T}$ and must be carried out by midwives in pregnancy examinations that have become standard. If I get information about mental health, of course I will ask the head of IBI and the closest midwife, but I have never heard information about mental health ... (Informant (7. Practical Midwife).

Table 5. In-depth Interviews of Mental Health Program

\begin{tabular}{|c|c|c|}
\hline Thematic & Answers & Conclusion \\
\hline $\begin{array}{l}\text { Mental } \\
\text { Health } \\
\text { Program } \\
\text { on } \\
\text { Pregnant } \\
\text { Woman }\end{array}$ & $\begin{array}{l}\text { - There has been a mental health program but it has not been socialized (inf 1) } \\
\text { - There has not been any mental health programs which has a specialty in antenatal care for } \\
\text { Bogor Regency (inf 2) } \\
\text { - Here has not been a mental health program but it was already included in a comprehensive } \\
\text { midwifery examination in midwifery care (inf 3) " } \\
\text { - There has not been any special mental health program for pregnant women but if } \\
\text { someone is stressed, the way she talks in not understandable, we just take her to a general } \\
\text { practitioner and still use } 10 \mathrm{~T} \text { (Inf } 4 \text { ) } \\
\text { - There has not been any specific program on mental health, as a reference for examinations } \\
\text { for pregnant women, we are still using the ANC } 10 \mathrm{~T} \text { standard (inf 5) }\end{array}$ & $\begin{array}{l}\text { The mental health } \\
\text { program for pregnant } \\
\text { women has already } \\
\text { existed but has not } \\
\text { been socialized to } \\
\text { primary facilities. }\end{array}$ \\
\hline
\end{tabular}

Based on a document review, mental health programs are special activities that must be carried out for pregnant women related to mental health.

Table 6. Triangulation of Informants on Maternal Mental Health Programs

\begin{tabular}{|l|l|l|l|}
\hline Thematic & Interview & Document Review & Interpretation \\
\hline $\begin{array}{l}\text { Mental Health } \\
\text { Program on } \\
\begin{array}{l}\text { Pregnant } \\
\text { Women }\end{array}\end{array}$ & $\begin{array}{l}\text { The mental health program for } \\
\text { pregnant women has already existed } \\
\text { primary facilities. }\end{array}$ & $\begin{array}{l}\text { The Maternal Mental } \\
\text { Health Program has not } \\
\text { been provided for all } \\
\text { pregnant women. }\end{array}$ & $\begin{array}{l}\text { Based on the results of interviews and } \\
\text { document review, the Mental Health Program } \\
\text { for pregnant women has already existed but has } \\
\text { not been socialized to the Primary facilities. }\end{array}$ \\
\hline
\end{tabular}

Barriers to Mental Health Screening: Obstacles in the implementation of mental health examinations and management are all attributes that do not support health examinations and promotion, such as the absence of operating procedures standard, there is no law so that the authority of midwives as examiners and mental health implementers is not implemented properly. The following data are the results of in-depth interviews with informants.

".

there should be no obstacles because there is already a module for midwives on how to train pregnant women to become Tough and Optimistic Mothers, equipped with videos and props in pregnant women class. However, there is still no operating procedure standard for the competence of midwives in mental health examinations. However, midwives should still be able to invite and train mothers to make MITO. It is hoped that the knowledge of midwives related to mental health needs to be improved, because it must be comprehensive, so it is necessary to increase the knowledge of midwives to know about maternal mental health during pregnancy ..... "Inf 1

“ There are already $S O P$ on the implementation of classes for pregnant women, but specifically regarding the mental health of pregnant women in independent midwife practices, there is no formulated about mental health so that there is an emphasis in the examination of pregnant women the importance of mental health and we will immediately formulate it with the Ministry of Health. There is no module book yet and it could be an obstacle but in fact the funds have not arrived to reproduce ..." inf 2 
“. Standard Operating Procedure for Mental Health Examination is not yet in the standard of examination for pregnant women,but it is only in the class of pregnant women, it sometimes mentioned about how pregnant women are still can have sexual with her husband, have jokes and look harmonious inf 4

Midwives' knowledge about mental health

Difficulty in Detecting Risk factors for $K S P R$, PASS, EDPS on pregnant women: Pregnancy needs to be managed properly, pregnancy as a physiological process can become pathological if it is not managed properly. The difficulty of careful management of pregnant women by health workers can reduce the delay in recognizing cases as a factor of delay.

Based on the document review, the difficulty of detection of risk factors for KSPR, PASS, EDPS is an important tool but they are difficult to apply during pregnancy examinations.

\section{Discussion}

Results of this study shows that public perception on mental health is still limited to mental disturbances, meanwhile it is defined as the state of well-being and productive. KIA BOOK has contained the pictures that illustrate the symptoms of mental problems. However, it is not yet perceived the concept of mental health as the state of well-being and productive during pregnancy.

Pregnant women around the world according to the Word Health Organization say that around $10 \%$ of pregnant women and $15 \%$ of women who have just given birth experience mental problems, especially depression. In developing countries this is even higher, namely $15.6 \%$ during pregnancy and $19.8 \%$ after childbirth ${ }^{7}$

this shows the need for knowledge both from pregnant women and from midwives as a place to pit pregnant women.

Besides increasing the knowledge of pregnant women by parents there is also the need for additional care in pregnancy by health workers (obstetricians, midwives, doctors and nurses). This effort is expected to be more empathetic so that young pregnant women want to come to health workers and can reduce the adverse effects psychologically during pregnancy both the acceptance of pregnancy and parenting at the time after giving birth to a baby.
Pregnancy is accompanied by mental problems and other problems that can endanger themselves and the child they are born with. Dangers for children born such as premature birth, low birth weight, etc. .. Besides that, the stigma is not good in the community, feeling themselves unable, low self-efficacy, and negative perceptions will affect the mother to come to a health facility.

A program to handle maternal and child health problems already exists, but the handling is prioritized (emphasized) on physical health, compared to mental health aspects that are often ignored in low and middle income countries including Indonesia (Atif, Lovell and Rahman, 2015). ${ }^{12}$ This is in line with the results of research which states that the mental health of mothers during pregnancy is a public health problem that tends to be ignored. Yet when referring to the World Health Organization (WHO) the definition of health is stated to be a complete state of physical, mental and social wellbeing and not just the absence of disease or weakness.

The definition of health combines a spiritual dimension, which in turn, ensures a holistic approach in providing mental health care. Comprehensive care is to meet not only the physical needs of patients but also their mental, social and emotional needs. Explained further, despite adopting/using the philosophy of holistic care, perinatal mental health problems often remain unnoticed/diagnosis is ignored, mothers with mental health problems often do not communicate with health workers and no further action is taken in midwifery authority

One of the main obstacles in improving mental health services in first-level of health facilities is the low number of trained health workers in providing mental health care (for mothers) (Saraceno et al., 2007). The assessment of mental health training needs for midwives, showed a lack of training on mental health issues related to pregnancy and childbirth (Simkhada et al., 2016). The results of this study indicated that only about $30 \%$ of midwives took adequate action.

The integrative review conducted by Bayrampour et al. (2018) stated that the low management/actions taken by midwives related to mental health are influenced by two main aspects,they are; obstacles from health workers and obstacles from the system. Internal obstacles from health workers include lack of training, 
lack of clarity on the scope of practice and limited time for examinations (ANC). Whereas barriers in the aspect of system consisting of unclear pathways, services that are not connected to each other, lack of local guidelines/ policies, unclear continuity of services, procedures, clinical support, supervision and accessible educational resources, lack of availability of referral resources, complex bureaucracy and challenges in expanding the scope of practice.

In order to improve mental health services for pregnant women, it is important to develop community mental health services, including appropriate training and supervision (Saraceno et al., 2007). Training, hiring and supporting midwives are essential to help the improvement of mental health service skills (Ghebrehiwet and Barrett, 2007).

This training focused on promoting mental health as a part of everyone's life and building skills to recognize mental health problems in pregnant women and new mothers (Hodgkinson et al., 2017). The problems related to the skills of midwives which are the subject of training include the following; (1) problems related to mental health training; (2) public attitudes; and (3) support for women. Training covers the benefits and limitations of training interventions; community attitudes lead to stigma and gender differences associated with mental health problems

\section{Conclusion}

Based on the document review, the definition of mental health is a condition of well-being in which a person realizes his own potential, can deal with stress normally in his life, work productively, and is able to contribute to himself or his community. ${ }^{14}$

The standard for pregnancy health care should be comprehensive. Therefore, deep understanding on pregnant women mental health is needed to construct high-quality health care for pregnant women to allow optimal preparation.

Ethical Clearance: Taken from University ethical committee.

\section{Source of Funding: Self}

\section{Conflict of Interest: Nil}

\section{References}

1. Anderson, et al. Point Prevalence of psychiatric disorder during the second trimester of pregnancy: Apopulation - based study; 2003

2. Ashley, J. M. et al. 'Estimated prevalence of antenatal depression in the US population', Archives of Women's Mental Health; 2016

3. Atif, N., Lovell, K. and Rahman, A. 'Maternal mental health: The missing " $\mathrm{m}$ " in the global maternal and child health agenda', Seminars in Perinatology. Elsevier; 2015

4. Bauer A,et al. The costs of perinatal mental health problems', Centre for Mental Health; 2014

5. Bayrampour, H. et al. 'A qualitative inquiry on pregnant women's preferences for mental health screening', BMC Pregnancy and Childbirth. BMC Pregnancy and Childbirth; 2017

6. Fairbrother, N. et al. 'Perinatal anxiety disorder prevalence and incidence', Journal of Affective Disorders. Elsevier; 2016

7. Ghebrehiwet, T., \& Barrett, T. Nurses and mental health services in developing countries. Lancet (London, England), 370(9592), 1016-1017. Robertson, E. et al. 'Antenatal risk factors for postpartum depression: A synthesis of recent literature', General Hospital Psychiatry; 2007

8. Publication, S. et al. 'Self-Esteem; a Brief Review; 2015

9. Robertson, E. et al. 'Antenatal risk factors for postpartum depression: A synthesis of recent literature', General Hospital Psychiatry; 2004

10. Saraceno, B., van Ommeren, M., Batniji, R., Cohen, A., Gureje, O., Mahoney, J., . . . Underhill, C. (2007). Barriers to improvement of mental health services in low-income and middle-income countries. The Lancet, 370(9593), 1164-1174. doi: https://doi.org/10.1016/S0140-6736(07)61263-X

11. Simkhada, B., Sharma, G., Pradhan, S., Van Teijlingen, E., Ireland, J., Simkhada, P., \& Devkota, B. Needs assessment of mental health training for Auxiliary Nurse Midwives: a cross-sectional 
survey. Journal of Manmohan Memorial Institute of Health Sciences, 2, 20-26, 2016.

12. Sukhato, et al. Efficacy of additional psychosocial intervention in reducing low birth weight and preterm birth in teenage pregnancy A systematic review and meta-analysis; 2015
13. Spedding, M. F. et al. 'Pregnant women's mental health literacy and perceptions of perinatal mental disorders in the Western Cape, South Africa', Mental Health and Prevention. Elsevier; 2018

14. World Health Organization. 'Promoting Mental Health: Concepts, Emerging evidence, Practice', Report of WHO Department of Mental Health and Substance Abuse; 2 